\title{
Validation of a QTL for Grain Size and Weight Using an Introgression Line from a Cross Between Oryza Sativa and Oryza Minuta
}

\section{Yue Feng}

China National Rice Research Institute

\section{Xiaoping Yuan}

China National Rice Research Institute

\section{Yiping Wang}

China National Rice Research Institute

\section{Yaolong Yang}

China National Rice Research Institute

\section{Mengchen Zhang}

China National Rice Research Institute

\section{Hanyong Yu}

China National Rice Research Institute

\section{Qun Xu}

China National Rice Research Institute

\section{Shan Wang}

China National Rice Research Institute

\section{Xiaojun Niu}

China National Rice Research Institute

Xinghua Wei ( $\nabla$ weixinghua@caas.cn )

China National Rice Research Institute https://orcid.org/0000-0002-0883-3694

\section{Original article}

Keywords: Oryza sativa, Oryza minuta, Introgressive line, Grain size and weight, Quantitative trait loci

Posted Date: August 17th, 2020

DOI: https://doi.org/10.21203/rs.3.rs-54218/v1

License: (1) (1) This work is licensed under a Creative Commons Attribution 4.0 International License.

Read Full License 


\section{Abstract}

Background: Grain size and weight are important target traits determining grain yield and quality in rice. Wild rice species possess substantial elite genes that can be served as an important resource for genetic improvement of rice. In this study, we identify and validate a novel QTL on chromosome 7 affecting the grain size and weight using introgression lines from cross of Oryza sativa and Oryza minuta.

Results: An introgression line 'IL188' has been achieved from a wild species Oryza minuta ( $2 n=48$, BBCC, W303) into $O$. sativa japonica Nipponbare. The $F_{2}$ and $F_{2: 3}$ populations derived from a cross between IL188 and Nipponbare were used to map QTLs for five grain size traits. A total of 12 QTLs for the five grain traits were identified on chromosomes $1,2,3,6,7$, and 8. The QTL $q G L 7$ on chromosome 7 was detected stably in the $F_{2}$ and $F_{2: 3}$ populations, and explained $15.09-16.30 \%$ of the phenotypic variance. To validate the effect of $q G L 7$, eight residual heterozygous line $(\mathrm{RHL})$ populations were developed through selfing four $\mathrm{F}_{2: 3}$ and four $\mathrm{F}_{2: 4}$ plants with different heterozygous segments for the target region. By further developing SSR and Indel markers in the target interval, $q G L 7$ was delimited to a $\sim 261 \mathrm{~kb}$ region between Indel marker Y7-12 and SSR marker Y7-38, which also showed significant effects on grain width and thousand grain weight. Scanning electron microscopy analysis of the glume's epidermal cells showed that the cell length and width of NIL- $q G L>1 L 188$ was higher than NIL- $q G L>N i p$, indicating that $q G L 7$ increases grain size and weight by regulating cell expansion.

Conclusions: In this study, we detected 12 QTLs regulating grain size and weight using an introgression line from a cross between an Oryza sativa and Oryza minuta. Of these loci, we confirmed and delimited the $q G L 7$ to a $\sim 261 \mathrm{~kb}$ region. These results provide a basis for map-based cloning of the $q G L 7$ gene and useful information for marker assisted selection in rice grain quality improvement.

\section{Background}

Rice (Oryza sativa L.) is one of the most important cereal crops in Asia and is the main staple food for the majority of peoples in the world. Breeding of high-yielding rice is crucial for meeting the food demand of the increasing world population (Ikeda et al. 2013). Grain yield in rice is determined by three major components: the number of panicles, the number of grains per panicle, and grain weight (Huang et al. 2013). Among these, the most reliable trait is grain weight, which is largely determined by grain size, which is specified by its three dimensions (length, width, and thickness) and the degree of filling (Xiong and Zhang 2010).

Grain size and weight are important components determining rice grain yield, and they are controlled by multiple quantitative trait loci (QTLs) (Zhang et al. 2012; Yu et al. 2018). To date, over 400 QTLs modulating grain size and weight have been identified and are distributed on each of rice's 12 chromosomes (Huang et al. 2013; Zuo and Li 2014; Kashif et al. 2020). However, only a few major QTLs including GS3, qSW5, GW2, qGL3/ GL3.1, GW8, GL7/ GW7, TGW6 and GS9 have been isolated by mapbased cloning methods (Mao et al. 2010; Shomura et al. 2008; Song et al. 2010; Qi et al. 2012; Zhang et 
al. 2012; Wang et al. 2012; Wang et al. 2015a; Wang et al. 2015b; Ishimaru et al. 2013; Zhao et al. 2018). The isolation of these genes has enhanced our knowledge of the molecular regulatory mechanisms responsible for grain size and weight (Song et al. 2008).

Oryza minuta $(2 n=48, B B C C)$ is an allotetraploid wild species, which is endemic to Philippines and Papua New Guinea. This species belongs to the Oryza officinalis complex and harbors useful genes for resistance to blast blight, bacterial blight, brown planthopper and sheath blight (Amante et al. 1992; Brar and Khush 1997). However, low crossability and limited recombination between unrelated genomes limit the transfer QTLs from Oryza minuta to cultivars. Following the availability of advanced backcross quantitative trait loci (AB-QTL) approach proposed by Tanksley and Nelson (1996), several studies have been reported to identify the QTLs controlling yield and quality-related traits and to simultaneously transfer them from wild to cultivated species (Xiao et al. 1998; Thomson et al. 2003; Yoon et al. 2006; Tian et al. 2006; Mallikarjuna Swamy et al. 2012; Yun et al. 2016). However, few attempts have been made to identify and capture yield-related QTLs from Oryza minuta into cultivars.

In the present study, we used an advanced across line IL188 from a cross between the japonica variety, Nipponbare, Oryza sativa and a wild accession, W303, Oryza minuta, as the donor parent, to map QTLs for rice grain size traits. The objectives of this study were: (1) to reliably identify novel genomic regions associated with grain size traits from W303 (Oryza minuta), (2) to evaluate the effects of introgressive segments on grain size traits, (3) to fine mapping the QTL- $q G L 7$ and validate the effects of $q G L 7$ for rice grain size and weight on chromosome 7.

\section{Results}

\section{Genetic background of IL188}

A total of 512 SSR markers were screened for polymorphism between W303 and Nipponbare. Among them, 185 markers produced polymorphic bands between the parents. These 185 polymorphic markers were further used to assay the genotype of IL188. Thirty of these markers (16.2\%) showed W303 genotype, which covered 11 regions distributing on six chromosomes. The introgressed segments distributed on chromosomes 1, 2 (two), 3, 5, 6 (two), 7 (two), and 8 (two), respectively (Fig. 3). These 30 markers were further used to genotype the $F_{2}$ and $F_{2: 3}$ populations derived from a cross between Nipponbare and IL188.

\section{Trait performance of the parents, F2 and F2:3 populations}

The phenotypic values of the two parents of five agronomic traits, including GL, GW, GT, LWR, and TGW were shown in Table 1. Compared with Nipponbare, IL188 had higher values for GL, GW, LWR, and TGW but lower values for $\mathrm{GT}$. The frequency distributions of the five grain size traits in the $F_{2}$ and $F_{2: 3}$ 
populations were shown in Fig. 4. All these traits showed continuous segregation and followed a near normal distribution in the both populations.

Table 1

The phenotypic performance of five grain size traits in IL188 and Nipponbare

\begin{tabular}{|lll|}
\hline Trait & Nip & IL188 \\
\hline GL $(\mathrm{mm})$ & $7.798 \pm 0.060$ & $9.416 \pm 0.133^{* *}$ \\
\hline GW $(\mathrm{mm})$ & $3.087 \pm 0.04$ & $3.347 \pm 0.072^{* *}$ \\
\hline LWR & $2.526 \pm 0.021$ & $2.819 \pm 0.042^{* *}$ \\
\hline GT (mm) & $2.295 \pm 0.035$ & $2.171 \pm 0.020^{* *}$ \\
\hline TGW (g) & $27.10 \pm 0.15$ & $34.40 \pm 0.19^{* *}$ \\
\hline $\begin{array}{l}\text { Nip, Nipponbare, GL, grain length, GW, grain width, LWR, the ratio of grain length to grain width, GT, } \\
\text { grain thickness, TGW, thousand grain weight. }{ }^{* *} \text { indicate significance at } P<0.01 .\end{array}$ \\
\hline
\end{tabular}

\section{Correlation analysis of five grain traits}

The correlation coefficients among the five grain traits in the $F_{2}$ and $F_{2: 3}$ populations were shown in Table 2. Significant correlation was observed for each pair-wise combination except that between GL and GT, LWR and TGW. In the both populations, GL showed positive correlation with GW, LWR and TGW, GW displayed strong positive correlation with GT and TGW, while LWR showed negative correlation with GW and GT. 
Table 2

Coefficients of pairwise correlation among five grain size traits in the $F_{2}$ and $F_{2: 3}$ populations

\begin{tabular}{|c|c|c|c|c|c|}
\hline & GL & GW & LWR & GT & TGW \\
\hline GL & & 0.276 ** & 0.536 ** & -0.025 & $0.598 * \star$ \\
\hline GW & $0.309 * *$ & & $-0.662^{\star \star}$ & 0.470 ** & $0.509 * \star$ \\
\hline LWR & $0.488 * \star$ & $-0.677 * \star$ & & $-0.439 * \star$ & 0.021 \\
\hline GT & 0.025 & $0.515^{\star \star}$ & -0.460 ** & & $0.438 * *$ \\
\hline TGW & $0.614^{\star *}$ & $0.547 * \star$ & -0.026 & $0.478 * \star$ & \\
\hline \multicolumn{6}{|c|}{$\begin{array}{l}\mathrm{GL} \text {, grain length }(\mathrm{mm}), \mathrm{GW} \text {, grain width }(\mathrm{mm}), \mathrm{LWR} \text {, the ratio of grain length to grain width, GT, grain } \\
\text { thickness }(\mathrm{mm}) \text {, TGW, thousand grain weight }(\mathrm{g}) \text {. The data of the left lower and the top right triangles } \\
\text { in the Table } 2 \text { are the correlation coefficients in } \mathrm{F}_{2} \text { and } \mathrm{F}_{2: 3} \text { population, respectively. }{ }^{*} \text { indicate } \\
\text { significance at } P<0.01 \text {. }\end{array}$} \\
\hline
\end{tabular}

\section{QTLs for grain size traits in the $F_{2}$ and $F_{2: 3}$ populations}

A total of 12 QTLs for five grain size traits were detected on chromosomes $1,2,3,6,7$, and 8 in the $F_{2}$ and $\mathrm{F}_{2: 3}$ populations (Table 3). The phenotypic variance explained by each QTL ranged from $4.72-16.30 \%$. Four of these regions were found to affect two traits. The RM7241-RM128 interval on the chromosome 1 and RM12923-RM5812 interval on chromosome 2 showed consistent effects on GL and LWR in both populations. In the RM7241-RM128 interval, $q G L 1$ and $q L W R 1$ explained phenotypic variances by $8.77 \%$ and $7.55 \%$ in the $F_{2}$ population, and $9.13 \%$ and $7.40 \%$ in the $F_{2: 3}$ population, respectively. In the RM12923-RM5812 interval, $q G L 2$ and $q L W R 2$ explained phenotypic variances by $8.77 \%$ and $7.55 \%$ in the $F_{2}$ population, and $9.13 \%$ and $7.40 \%$ in the $F_{2: 3}$ population, respectively. The enhancing alleles of these QTLs all derived from IL188. The RM500-RM429 interval on chromosome 7 showed consistent effects on GL and TGW in the both populations. The $q G L 7$ and $q T G W 7$ explained phenotypic variances by $16.30 \%$ and $9.97 \%$ in the $F_{2}$ population, and $15.09 \%$ and $6.65 \%$ in the $F_{2: 3}$ population, respectively. The enhancing alleles of the two QTLs also derived from IL188. The RM3845-RM6948 on chromosome 8 exhibited significant effects on GT and LWR only in the $\mathrm{F}_{2: 3}$ population. The $q G T 8$ and $q L W R 8$ explained $7.41 \%$ and $4.72 \%$ of phenotypic variances, with enhancing alleles derived from Nippobare and IL188, respectively. The other four regions, which covered RM6307-RM5807, RM3199-RM3684, RM7158RM276, RM408-RM3702 on chromosome 2, 3, 6 and 8, respectively, were each detected for a single trait, with $R^{2}$ ranging from $4.85-7.06 \%$. 
Table 3

QTLs detected for five grain size traits in $\mathrm{F}_{2}$ and $\mathrm{F}_{2: 3}$ populations

\begin{tabular}{|c|c|c|c|c|c|c|c|c|c|}
\hline Trait & QTL & Chr. & Interval & $F_{2}$ & & & $F_{2: 3}$ & & \\
\hline & & & & $\angle O D$ & $A$ & $R^{2}(\%)$ & $\angle O D$ & $A$ & $R^{2}(\%)$ \\
\hline GL & $q G L 1$ & 1 & RM7341-RM128 & 4.55 & -0.142 & 8.77 & 4.35 & -0.144 & 9.13 \\
\hline GL & $q G L 2$ & 2 & RM12924-RM5812 & 4.20 & -0.120 & 6.90 & 3.81 & -0.123 & 7.09 \\
\hline GL & $q G L 7$ & 7 & RM500-RM429 & 7.34 & -0.190 & 16.30 & 6.15 & -0.18 & 15.09 \\
\hline GL & $q G L 8$ & 8 & RM408-RM3702 & 2.82 & -0.066 & 5.13 & 2.65 & -0.060 & 4.85 \\
\hline GW & $q G W 3$ & 3 & RM3199-RM3684 & 2.55 & -0.047 & 5.77 & & & \\
\hline LWR & $q L W R 1$ & 1 & RM7341-RM128 & 2.92 & -0.051 & 7.55 & 2.81 & -0.050 & 7.40 \\
\hline LWR & $q L W R 2$ & 2 & RM12924-RM5812 & 2.69 & -0.040 & 5.02 & 2.74 & -0.043 & 5.68 \\
\hline LWR & $q L W R 8$ & 8 & RM3845-RM6948 & & & & 2.52 & -0.038 & 4.72 \\
\hline GT & $q G T 6$ & 6 & RM7158-RM276 & 4.26 & 0.021 & 5.68 & 4.96 & 0.032 & 6.25 \\
\hline GT & $q G T 8$ & 8 & RM3845-RM6948 & & & & 2.59 & 0.024 & 7.41 \\
\hline TGW & qTGW2 & 2 & RM6307-RM5807 & 2.57 & -0.072 & 7.06 & 2.54 & -0.070 & 6.75 \\
\hline TGW & qTGW7 & 7 & RM500-RM429 & 4.56 & -0.070 & 9.97 & 3.74 & -0.061 & 6.65 \\
\hline \multicolumn{10}{|c|}{$\begin{array}{l}\mathrm{GL} \text {, grain length }(\mathrm{mm}), \mathrm{GW} \text {, grain width }(\mathrm{mm}) \text {, LWR, the ratio of grain length to grain width, GT, grain } \\
\text { thickness }(\mathrm{mm}) \text {, TGW, thousand grain weight }(\mathrm{g}) \text {. A, Additive effect of QT L, Positive value and } \\
\text { negative value of additive effects represented the Nipponbare and IL188 alleles, respectively. } R, \\
\text { variance explained by the QTL. }\end{array}$} \\
\hline
\end{tabular}


Table 4

QTLs detected for three grain traits in the $\mathrm{R} 1-\mathrm{R} 8$ populations

\begin{tabular}{|c|c|c|c|c|c|}
\hline Population & Marker interval & Trait & $\angle O D$ & $A$ & $R^{2}(\%)$ \\
\hline \multirow[t]{3}{*}{ R1 } & RM1135-RM11 & GL & 0.27 & -0.038 & 1.41 \\
\hline & & GW & 1.24 & 0.041 & 4.61 \\
\hline & & TGW & 0.38 & 0.039 & 1.38 \\
\hline \multirow[t]{3}{*}{ R2 } & RM11-Y7-2 & $\mathrm{GL}$ & 7.35 & -0.115 & 19.54 \\
\hline & & GW & 9.37 & -0.065 & 21.65 \\
\hline & & TGW & 11.00 & -0.621 & 16.09 \\
\hline \multirow[t]{3}{*}{ R3 } & RM11-Y7-2 & $\mathrm{GL}$ & 5.07 & -0.109 & 15.46 \\
\hline & & GW & 3.29 & -0.050 & 10.24 \\
\hline & & TGW & 7.16 & -0.907 & 16.86 \\
\hline \multirow[t]{3}{*}{ R4 } & RM11-RM21734 & $\mathrm{GL}$ & 0.32 & -0.041 & 1.80 \\
\hline & & GW & 1.03 & 0.002 & 0.06 \\
\hline & & TGW & 0.26 & 0.141 & 1.03 \\
\hline \multirow[t]{3}{*}{ R5 } & Y7-4-RM21787 & $\mathrm{GL}$ & 0.45 & -0.025 & 1.39 \\
\hline & & GW & 0.14 & 0.001 & 0.04 \\
\hline & & TGW & 0.30 & -0.096 & 0.48 \\
\hline \multirow[t]{3}{*}{ R6 } & RM21787-Y7-13 & $\mathrm{GL}$ & 17.99 & -0.129 & 48.52 \\
\hline & & GW & 4.08 & -0.026 & 16.44 \\
\hline & & TGW & 8.04 & -0.595 & 25.38 \\
\hline \multirow[t]{3}{*}{ R7 } & RM21787-Y7-12 & $\mathrm{GL}$ & 1.91 & -0.077 & 7.33 \\
\hline & & GW & 1.25 & -0.007 & 0.40 \\
\hline & & TGW & 1.72 & -0.263 & 1.87 \\
\hline \multirow[t]{3}{*}{ R8 } & Y7-4-RM455 & $\mathrm{GL}$ & 5.81 & -0.074 & 18.12 \\
\hline & & GW & 3.61 & -0.031 & 12.77 \\
\hline & & TGW & 3.21 & -0.494 & 9.22 \\
\hline $\begin{array}{l}\text { GL, grain ler } \\
\text { Positive valı } \\
\text { respectively. }\end{array}$ & $\begin{array}{l}\text {, GW, grain width } \\
\text { gative value of ad } \\
\text { ice explained by th }\end{array}$ & $\begin{array}{l}\text { thous } \\
\text { s repre }\end{array}$ & $\begin{array}{l}\text { ain we } \\
d \text { the N }\end{array}$ & $\begin{array}{l}\text { A, add } \\
\text { are and }\end{array}$ & $\begin{array}{l}\text { ffect, } \\
\text { alleles, }\end{array}$ \\
\hline
\end{tabular}


Among these regions, the RM500-RM429 interval on chromosome 7 showed the largest effect for GL and relatively stable QTLs for TGW. Therefore, the region was chosen for further validation. For ease of description, the $q G L 7$ and $q T G W 7$ detected in this region were integrated as $q G L 7$.

\section{Substitution mapping of qGL7}

Four NIL-F 2 populations carrying heterozygous segments overlapped in the RM500-RM429 interval were constructed, including R1, R2, R3 and R4. Significant genotypic effects were detected for all the three grain size traits in R2 and R3. In the two populations, the additive effects were 0.115 and 0.109 for $\mathrm{GL}$, 0.065 and 0.050 for GW, 0.621 and 0.907 for TGW, explained phenotypic variances by $19.54 \%$ and $15.46 \%, 21.65 \%$ and $10.24 \%$, and $16.09 \%$ and $16.86 \%$. The enhancing allele was derived from IL 188 , the same as what was found in the $\mathrm{F}_{2}$ and $\mathrm{F}_{2: 3}$ populations. The additive effects and $R^{2}$ were similar between $\mathrm{R} 2$ and R3, indicated that $q G L 7$ located in the common segregating regions of the two populations. In R1 and R4, no significant effect was detected for any traits, indicated that $q G L 7$ located outside of segregating regions of the two populations. As shown in Fig. 5, this is an interval flanked by markers Y7-3 and Y7-4, corresponding to a 725-kb region in the Nipponbare genome.

Following the update target regions, other four $\mathrm{NIL}-\mathrm{F}_{2}$ populations were developed, including R5, R6, R7 and R8. Significant genotypic effects were detected in R6 and R8, but not in R5 and R7. In R6 and R8, the additive effects were 0.129 and 0.074 for GL, 0.026 and 0.031 for GW, 0.595 and 0.494 for TGW, explained phenotypic variances by $48.52 \%$ and $18.12 \%, 16.44 \%$ and $12.77 \%$, and $25.38 \%$ and $9.92 \%$. Again, the enhancing allele was derived from IL188. These results indicated that $q G L 7$ was located within the common segregating regions of R6 and R8 but outside the segregating region of R5 and R7. Consequently, $q G L 7$ was delimited into a $261-\mathrm{kb}$ region flanked by $\mathrm{Y} 7-12$ and $\mathrm{Y} 7-38$.

The homozygous plants were selected from R6 and R8. They were selfed to develop two NIL populations. The effect of $q G L 7$ was further validated using these two populations. Compared with NIL- $q G L 7 N$ ip, the GL and GW in the NIL- $q G L 7 L 188$ were significantly larger (Fig. 7A-D), thus resulting in a larger TGW. These indicated that $q G L 7$ had stable effects on grain size traits.

In addition, we examined the cell length and width of epidermal cells of the outer and inner spikelet hulls of NIL- $q G L>N$ Nip and NIL- $q G L>12188$ by scanning electron microscopy. Both the length and width of epidermal cells of the outer and inner spikelet hulls were increased in NIL- $q G L 7{ }^{2} 188$ compared with those in NIL- $q G L 7$ Nip (Fig. 7E-L). These results indicate that $q G L 7$ regulates grain size by promoting cell expansion.

\section{Discussion}

Common wild rice is the wild ancestor of cultivated rice (Second, 1982; Oka, 1988; Wang et al. 1992). As the ancestor of cultivated rice, wild rice has been well recognized as an extremely important resource for 
rice improvement, since it carries many beneficial agronomic traits which have been lost in the cultivated rice through natural and human selection (Sun et al. 2001; Sakai and Itoh 2010). In the present study, an advanced backcross line, IL188, was developed from a cross between Nipponbare and 0 . minuta. The $F_{2}$ and $F_{2: 3}$ populations derived from a cross between Nipponbare and IL188 was used to identify the QTLs controlling grain size and grain weight. A total of 12 putative QTLs for grain size and grain weight were detected in the $F_{2}$ and $F_{2: 3}$ populations, and 9 of which were commonly detected in both populations.

A comparison of the QTL regions from this study with those seen in previous rice linkage maps (http://www.gramene.org) revealed that six regions were shared across studies. For GL and LWR, one QTL was detected in the interval RM7341-RM128 on chromosome 1. Wan et al. (2005) also detected a stable QTL for the same traits in the similar regions on chromosome 1, and Qi et al. (2017) detected a QTL for LWR closely linked with the marker RM128. One locus associated with GL and LWR ( $q G L 2$, and $q L W R 2)$ were located in the interval RM12924-RM5812 on chromosome 2. Interestingly, Yoon et al. (2006) confirmed a locus associated with TGW, GW, GT, and LWR in the same region using an advanced backcross population between $O$. Grandiglumis and $O$. sativa. Two QTLs for GW and GT were respectively located in the vicinity of QTLs detected in previous studies (Yoon et al. 2006; Mallikarjuna Swamy et al. 2012; Qi et al. 2017). In our study, one QTL was detected for TGW in the interval RM6307RM5807 on chromosome 2, and Xue et al. (2019) also detected a QTL for TGW in the nearby region.

More importantly, one major QTL, $q G L 7$, was detected for GL and TGW in the interval RM500-RM429 on chromosome 7 in the $F_{2}$ and $F_{2: 3}$ populations. The 0 . minuta introgressive line alleles could increase $\mathrm{GL}$ and TGW. The qGL7 could explain $15.09-16.30 \%$ and $6.65-9.97 \%$ of the phenotypic variation for GL and TGW, respectively. The 0 . minuta allele at locus $q G L 7$ increased $G L$ and TGW by an average of $0.19 \mathrm{~mm}$ and $0.65 \mathrm{~g}$, respectively. Interestingly, Rahman et al. (2007) also detected a QTL for GL and TGW in the same region using an $\mathrm{F}_{2: 3}$ population between $O$. minuta introgression line and $O$. sativa. This result indicated that there really exist a stable QTL controlling grain size and grain weight, and the 0 . minuta allele could positively regulate grain size and grain weight. As we known, some major-effect QTLs for grain size and weight on chromosome 7 have been fine mapped and cloned in previous studies. Bai et al. (2010) detected a pleiotropic QTL for grain size and this QTL $q G L 7$ was narrowed down to within a 258$\mathrm{kb}$ region. Shao et al. and Qiu et al. identified a major QTL GS7/ qSS7 on the long arm of chromosome 7 for grain size. Subsequently, This GL7/GW7 gene has been cloned by Wang et al. (2015a) and Wang et al. (2015b). They have found that copy number variations at GL $7 / G W 7$ locus cause elevated expression of $G L 7$ and thus an increase in grain length. The grain size gene $G L W 7$, encoding the plant-specific transcription factor OsSPL13, has been isolated and functionally characterized using GWAS approach (Si et al. 2016). Xu et al. (2015) identified a dominant big grain mutant BG2 that encoded a cytochrome P450, OsCYP78A13 on chromosome 7. Here, we have defined the locus $q G L 7$ to a $261 \mathrm{~kb}$ region on the long arm of chromosome 7. By comparing the physical location of $q G L 7$ with the reported grain size QTLs on chromosome 7, we found that $q G L 7$ is a novel QTL for regulating rice grain size. 
Classical quantitative genetics assumes that trait correlations are the result of either pleiotropic effects or the tight linkage of genes (Wan et al. 2005). In this study, qGL 1/ qLWR1 and $q G L 2 / q L W R 2$ were mapped in the same interval on chromosome 1 and chromosome 2, respectively, and the positive alleles were all derived from 0 . minuta. As well, $q G L 7$ and $q T G W 7$ shared the same confidence interval on chromosome 7 and their effect acted in the same direction. Co-localization of these QTLs, as the result of either pleiotropic effects or close linkage, could provide an explanation for the genetic basis of high trait correlations, which ranged from $0.488^{\star \star}$ between GL and LWR to $0.614^{\star \star}$ between GL and TGW.

Transfer and utilization useful genes from wild rice into cultivated varieties are effective and aim to improve grain yield, quality, and crop genetic diversity (Brar and Khush 1997; Xie et al. 2008; Yun et al. 2016; Qi et al. 2017). However, efforts to improve rice grain traits of modern cultivars using O. minuta as donor parents are limited. In the present study, 0 . minuta alleles increase rice grain traits in the Nipponbare background at most QTLs, revealing the possibility that $O$. minuta alleles could improve grain traits. Although a number of genes/QTLs involved in the regulation of grain size have been cloned in rice, the molecular mechanisms of how grain size is regulated remain unknown. In this study, we found that $q G L 7$ could increase both grain length and grain weight, and the isolation of $q G L 7$ will be beneficial in better understanding of the regulation mechanism of grain size in rice. In addition, our continuous work will be helpful in improving rice yield and quality by molecular design breeding.

\section{Conclusions}

An introgression line IL188 was identified, which exhibited increased grain size and weight. A total of 12 QTLs for five grain traits were detected using $F_{2}$ and $F_{2: 3}$ populations derived from crosses between IL188 and Nipponbare. One of the QTLs, $q G L 7$ was delimited to a $\sim 261 \mathrm{~kb}$ region on the long arm of chromosome 7 . The $q G L 7$ increases grain size and weight by regulating cell expansion. These results will be helpful not only for understanding the genetic basis of grain size traits, but also simultaneously improving grain size and weight through marker-assisted selection (MAS) in rice breeding programs.

\section{Materials And Methods}

\section{Plant materials}

The introgression line, IL188, derived from an interspecific cross between Oryza sativajaponica Nipponbare and a wild species Oryza minuta W303 collected from the Germplasm Resource Center of IRRI, followed by three backcrosses with Nipponbare and aided by embryo rescue and subsequently self-pollinated for four generations. IL188 showed significantly longer grain length and higher grain weight than the recurrent parent Nipponbare (Fig. 1). To elucidate the genetic basis of the grain size and weight variation, an $\mathrm{F}_{2}$ population consisting of 166 individuals was constructed by selfing the $F_{1}$ between the female parent IL188 and male parent Nipponbare, and the $F_{2: 3}$ population was derived from the selfed seeds of the $F_{2}$ plants. 
Following the initial outcome of QTL analysis, four residual heterozygous plants were selected from the $F_{2: 3}$ populations, carrying sequential heterozygous segments covering the interval RM500-RM429. They were selfed, and four NIL-F $F_{2}$ populations were constructed. They contained 180, 184, 184 and 195 plants and were named as R1, R2, R3 and R4, respectively.

Four other plants were further selected from the R3 population carrying sequential heterozygous segments covering the interval Y7-3-Y7-4. They were selfed, and four NIL-F $F_{2}$ populations were constructed. They contained 130, 144, 146 and 140 plants and were named as R5, R6, R7 and R8, respectively. Non-recombinant homozygous plants were further identified in the R6 and R8 populations and selfed. Two sets of NILs were developed, each consisting of 20 IL188 homozygous lines and 20 Nipponbare homozygous lines.

The $\mathrm{F}_{2}$ and $\mathrm{F}_{2: 3}$ populations were grown at the Hangzhou Experiment Station of China Rice Research Institute (CNRRI), Zhejiang ( $30^{\circ} 32^{\prime}$, E $120^{\circ} 12^{\prime}$ ), China, and the Lingshui Experiment Station of CNRRI, Hainan ( $\left.18^{\circ} 48^{\prime}, E 110^{\circ} 02^{\prime}\right)$, China, in the summer and winter of 2014 . The NIL-F 2 populations and two sets of NILs were planted at the Hangzhou Experiment Station of CNRRI in the summer of 2015, 2016 and 2017. The $F_{2}$ and NIL-F $F_{2}$ populations were planted with $20 \mathrm{~cm}$ between plants and $30 \mathrm{~cm}$ between rows. The $F_{2: 3}$ families and two sets of NILs were grown in a randomized complete block design with two replications, five rows per plot, 8 plants per row, $20 \mathrm{~cm}$ between plants within each row and $30 \mathrm{~cm}$ between rows. The field management followed the standard agronomic practices.

\section{Grain size trait evaluation}

For the $F_{2}$ and NIL-F $F_{2}$ populations, the plants were individually harvested for trait evaluation. For the $F_{2: 3}$ population and NILs- $q G L 7 \mathrm{Nip}$ and NILs- $q G L 7^{L 188}$, ten plants in each line was harvested in bulk for trait evaluation. Five grain size traits were evaluated in each population. For grain length (GL), grain width (GW) and grain thickness (GT), 20 full-filled rice grains were randomly selected and individually measured using an electronic digital display Vernier caliper. The averaged values of the 20 grains were used for data analysis. The grain length-width ratio (LWR) is equal to GL divided by its GW. Thousand grain weight (TGW) was evaluated by measuring the weight of 200 randomly selected full-filled grains per $\mathrm{F}_{2}$ plant. The phenotypic evaluations of $F_{2: 3}$ family, NIL-F $F_{2}$ population and NIL lines were the same as those for $F_{2}$ plants described above.

\section{Scanning Electron Microscopy}

The spikelets of NIL- $q G L 7$ Nip and NIL- $q G L 7^{L 188}$ were collected at maturity stage. The samples were fixed in FAA solution (formalin: glacial acetic acid: ethanol in 1:1:18 ratio by volume) at $4{ }^{\circ} \mathrm{C}$ for $24 \mathrm{~h}$, then dehydrated by a graded ethanol series, and were dried by critical-point drying method. The samples were 
observed under the scanning electron microscope (HITACHI, S-3000N). The spikelet epidermal cell size was measured using image $\mathrm{J}$ software.

\section{DNA extraction and molecular marker analysis}

DNA was extracted from fresh leaves samples following the CTAB method (Murray and Thompson 1980) with minor modifications. A total of 512 SSR markers with good genome coverage were selected to detect the polymorphisms between parents W303 and Nipponbare, 185 of which distributed across all 12 chromosomes showed polymorphisms between the two parents. Furthermore, 30 polymorphic SSR markers between IL188 and Nipponbare were used to genotype the $F_{2}$ and $F_{2: 3}$ populations. Sixteen markers were used for fine mapping (Table S1).

\section{Linkage map construction and data analysis}

A genetic linkage map was constructed using MAPMAKER/EXP version 3.0 (Lander et al. 1987). The Kosambi mapping function (Kosambi) was used to transform the recombination frequency into $\mathrm{cM}$. Composite interval mapping (CIM) was carried out to scan the introgressive genomic regions for putative QTLs using Windows QTL Cartographer 2.5 (http:// statgen.ncsu.edu/qtlcart/WQTLCart.htm). The LOD threshold of 2.5 was used for declaring the presence of a putative QTL in a given genomic region. Nomenclature of QTLs was conducted as described by McCouch et al. (1997).

Phenotypic differences between IL188 and Nipponbare and between two homozygous lines in the NIL populations were compared using the Student's test. Correlation analysis of grain size traits were performed using SPSS software.

\section{Abbreviations}

QTL: Quantitative trait locus; IL: Introgression line; RHL: Residual heterozygous line; SSR: Simple sequence repeat; GWAS: Genome wide association study; MAS: Molecular assisted selection; NIL: Near isogenic line

\section{Declarations}

\section{Acknowledgments}

We wish to thank Dr. Zhang Zhenhua for careful corrections and valuable suggestions on the revision.

\section{Authors' Contributions}


YF designed the experiments; XY, YW, YY, MZ, HY, QX, SW, and XN performed experiments and analyzed the data; $Y F$ and $X W$ wrote the manuscript. All authors read and approved the final version of the manuscript.

\section{Funding}

This study was supported by the Major Scientific and Technological Project for New Varieties Breeding of Zhejing Province (2016C02050-6-1), Zhejiang Provincial Natural Science Foundation of China (LY15C130005).

\section{Availability of Data and Materials}

The datasets supporting the conclusions of this article are included within the article.

\section{Consent for Publication}

All authors are consent for publication.

\section{Competing interests}

The authors declare that they have no competing interests.

\section{References}

Amante-Bordeos A, Sitch LA, Nelson R, Dalmacio RD, Oliva NP, Aswidinnoor H, Leung H (1992) Transfer of bacterial blight and blast resistance from the tetraploid wild rice Oryza minuta to cultivated rice, Oryza sativa. Theor Appl Genet 84:345-354

Bai XF, Luo LJ, Yan WH, Kovi MR, Zhan W, Xing YZ (2010) Genetic dissection of rice grain shape using a recombinant inbred line population derived from two contrasting parents and fine mapping a pleiotropic quantitative trait locus $q G L 7$. BMC genet 11:16

Brar DS, Khush GS (1997) Alien introgression in rice. Plant Mol Biol 35:35-47

Huang R, Jiang L, Zheng J, Wang T, Wang H, Huang Y, Hong Z (2013) Genetic bases of rice grain shape: so many genes, so little known. Trends Plant Sci 18:218-226

Ikeda M, Miura K, Aya K, Kitano H, Matsuoka M (2013) Genes offering the potential for designing yieldrelated traits in rice. Curr Opin Plant Biol 16:213-220 
Huang RY, Jiang LR, Zheng JS, Wang TS, Wang HC, Huang YM, Hong ZJ (2013) Genetic bases of rice grain shape: so many genes, so little known. Trends Plant Sci 18:218-226

Ishimaru K, Hirotsu N, Madoka Y, Murakami N, Hara N, Onodera H,

Kashiwagi T, Ujiie K, Shimizu B, Onishi A, Miyagawa H, Katoh E (2013) Loss of function of the IAAglucose hydrolase gene TGW6 enhances rice grain weight and increases yield. Nat Genet 45(6):707-711

Kashif H, Zhang YX, Workie A, Aamir R, Adil A, Md. Hasanuzzaman R, Wang H, Shen XH, Cao LY, Cheng $\mathrm{SH}$ (2020) Association mapping of quantitative trait loci for grain size in introgression line derived from oryza rufipogon. Rice Sci 27(3):246-254

Lander ES, Green P, Abbrahamson J, Barlow A, Daly MJ, Lincoln SE, Newburg L (1987) MAPMAKER: an interactive computer package for constructing primary genetic linkage maps of experimental and natural populations. Genomics 1:174-181

Mallikarjuna Swamy BPM, Kaladhar K, Shobha Rain N, Prasad GSV, Viraktamath BC, Ashok Reddy G, Sarla N (2012) QTL analysis for grain quality traits in $2 \mathrm{BC}_{2} \mathrm{~F}_{2}$ populations derived from crosses between Oryza sativa cv Swarna and 2 accessions of O. nivara. J Hered 103(3):442-452

Mao HL, Sun SY, Yao JL, Wang CR, Yu SB, Xu CG, Li XH, Zhang QF (2010) Linking differential domain functions of the GS3 protein to natural variation of grain size in rice. Proc Natl Acad Sci USA 107:1957919584

McCouch SR, Cho YG, Yano M, Paul E, Blinstrub M, Morishima H, Kinoshita T (1997) Report on QTL nomenclature. Rice Genet Newsl 14:11-13

Murray MG, Thompson WF (1980) Rapid isolation of high molecular weight plant DNA. Nucleic Acids Res $8: 4321-4325$

Oka H I (1988) Origin of cultivated rice. Developments in Crop Science. Vol. 14, Japan Scientific Society Press okyo and Elsevier. Amsterdam.

Qi L, Sun Y, Li J, Sun L, Zheng XM, Wang X, Li K, Yang Q, Qiao W (2017) Identify QTLs for grain size and weight in common wild rice using chromosome segment substitution lines across six environments. Breeding Sci 67:472-482

Qi P, Lin YS, Song XJ, Shen JB, Huang W, Shan JX, Zhu MZ, Jiang LW, Gao JP, Lin HX (2012) The novel quantitative trait locus GL3.1 controls rice grain size and yield by regulating Cyclin-T1;3. Cell Res 22(12):1666-1680

Qiu XJ, Gong R, Tan YB, Yu SB (2012) Mapping and characterization of the major quantitative trait locus qSS7 associated with increased length and decreased width of rice seeds. Theor Appl Genet 125(8):1717-1726

Page 14/21 
Rahman ML, Chu SH, ChoiM, Qiao YL, Jiang WZ, Piao R, Khanam S, Cho Y, Jeung J, Jena KK, Koh H (2007) Identification of QTLs for some agronomic traits in rice using an introgression line from Oryza minuta. Mol Cells 24(1): 16-26

Sakai H, Itoh T (2010) Massive gene losses in Asian cultivated rice unveiled by comparative genome analysis. BMC Genom 11:121

Second G (1982) Origin of the genic diversity of cultivated rice (Oryza spp.): study of the polymorphism scored at 40 isozyme loci. (Jpn J Genet) 57:25-57

Shao GN, Wei XJ, Chen ML, Tang SQ, Luo J, Jiao GA, Xie LH, Hu PS (2012) Allelic variation for a candidate gene for GS7, responsible for grain shape in rice. Theor Appl Genet 125(6):1303-1312

Shomura A, Izawa T, Ebana K, Ebitani T, Kanegae H, Konishi S, Yano M (2008) Deletion in a gene associated with grain size increased yields during rice domestication. Nat Genet 40(8):1023-1028

Si LZ, Chen JY, Huang XH, Gong H, Luo JH, Hou QQ, Zhou TY, Lu TT,

Zhu JJ, Shangguan YY, Chen EW, Gong CX, Zhao Q, Jing YF, Zhao Y, Li Y, Cui LL, Fan DL, Lu YQ, Weng QJ, Wang YC, Zhan QL, Liu KY, Wei XH, An K, An G, Han B (2016) OSSPL 13 controls grain size in cultivated rice. Nat Genet 48:447-456

Song XJ, Ashikari M (2008) Toward an optimum return from crop plants. Rice 1:135-143

Song XJ, Huang W, Shi M, Zhu MZ, Lin HX (2010) A QTL for rice grain width and weight encodes a previously unknown RING-type E3 ubiquitin ligase. Nat Genet 39:623-630

Sun CQ, Wang XK, Li ZC, Yoshimura A, Iwata N (2001) Comparison of the genetic diversity of common wild rice (Oryza rufipogon Griff.) and cultivated rice (O. sativa L.) using RFLP markers. Theor Appl Genet 102:157-162

Swamy BPM, Kaladhar K, Rani NS, Prasad GSV, Viraktamath BC, Reddy GA, Sarla N (2012) QTL analysis for grain quality traits in $2 \mathrm{BC}_{2} \mathrm{~F}_{2}$ populations derived from crosses between Oryzasativa cv Swarna and 2 accessions of $O$. nivara. J Hered 103(3):442-452

Tanksley SD, Nelson JC (1996) Advanced backcross QTL analysis: a method for the simultaneous discovery and transfer of valuable QTLs from unadapted germplasm into elite breeding lines. Theor Appl Genet 92:191-203

Thomson MJ, Tai TH, McClung AM, Lai XH, Hinga ME, Lobos KB, Xu Y, Martinez CP, McCouch SR (2003) Mapping quantitative trait loci for yield, yield components and morphological traits in an advanced backcross population between Oryza rufipogon and the Oryza sativa cultivar Jefferson. Theor Appl Genet 107:479-493 
Tian F, Li DJ, Fu Q, Zhu ZF, Fu YC, Wang XK, Sun CQ (2006) Construction of introgression lines carrying wild rice (Oryza rufipogon Griff.) segments in cultivated rice (Oryza sativa L.) background and characterization of introgressed segments associated with yield-related traits. Theor Appl Genet $112: 570-580$

Wan XY, Wan JM, Weng JF, Jiang L, Bi JC, Wang CM, Zhai HQ (2005) Stability of QTLs for rice grain dimension and endosperm chalkiness characteristics across eight environments. Theor Appl Genet 110:1334-1346

Wang SK, Li S, Liu Q, Wu K, Zhang JQ, Wang SS, Wang Y, Chen XB, Zhang Y, Gao CX, Wang F, Huang HX, Fu XD (2015a) The OSSPL16-GW7 regulatory module determines grain shape and simultaneously improves rice yield and grain quality. Nat Genet 47(8):949-954

Wang SK, Wu K, Yuan QB, Liu XY, Liu ZB, Lin XY, Zeng RZ, Zhu HT, Dong GJ, Qian Q, Zhang GQ, Fu XD (2012) Control of grain size, shape and quality by OSSPL 16 in rice. Nat Genet 44(8):950-954

Wang YX, Xiong GS, Hu J, Jiang L, Yu H, Xu J, Fang YX, Zeng LJ, Xu EB, Xu J, Ye WJ, Meng XB, Liu RF, Chen HQ, Jing YH, Wang YH, Zhu XD, Li JY, Qian Q (2015b) Copy number variation at the GL 7 locus contributes to grain size diversity in rice. Nat Genet 47(8):944-948

Wang ZY, Second G, Tanksley SD (1992) Polymorphism and phylogenetic relationships among species in the genus Oryza as determined by analysis of nuclear RFLPs. Theor Appl Genet 83:565-581

Xiao JH, Li JM, Grandillo S, Ahn SN, Yuan LP, Tanksley SD, McCouch SR (1998) Identification of traitimproving quantitative trait loci alleles from a wild rice relative, Oryza rufipogon. Genetics 150:899-909

Xie X, Song MH, Jin F, Ahn SN, Suh JP, Hwang HG, Kim YG, McCouch SR (2008) Fine mapping of a yieldenhancing QTL cluster associated with transgressive variation in an Oryza sativa $\times$ O. rufipogon cross. Theor Appl Genet 116:613-622

Xie XB, Song MH, Jin FX, Ahn SN, Suh JP, Hwang HG, McCouch SR (2006) Fine mapping of a grain weight quantitative trait locus on rice chromosome 8 using near-isogenic lines derived from a cross between Oryza sativa and Oryza rufipogon. Theor Appl Genet 113:885-894

Xiong YZ, Zhang QF (2010) Genetic and molecular bases of rice yield. Annu Rev Plant Biol 61:421-442

Xu F, Fang J, Ou SJ, Gao SP, Zhang FX, Du L, Xiao YH, Wang HR, Sun XH, Chu JF, Wang GD, Chu CC (2015) Variations in CYP78A13 coding region influence grain size and yield in rice. Plant Cell \& Environ 38(4):800-811

Xue P, Zhang YX, Lou XY, Zhu AK, Chen YY, Sun B, Yu P, Cheng SH, Cao LY, Zhan XD (2018) Mapping and genetic validation of a grain size QTL qGS7.1 in rice (Oryza sativa L.). J Integr Agric 18(8):1838-1850 
Yoon DB, Kang KH, Kim HJ, Ju HG, Kwon SJ, Suh JP, Jeong OY, Ahn SN (2006) Mapping quantitative trait loci for yield components and morphological traits in an advanced backcross population between Oryza grandiglumis and the $O$. sativa japonica cultivar Hwaseongbyeo. Theor Appl Genet 112:1052-1062

Yu JP, Miao JL, Zhang ZY, Xiong HY, Zhu XY, Sun XM, Pan YH, Liang YT, Zhang Q, Rehman RMA, Li JJ, Zhang HL, Li ZC (2018) Alternative splicing of OsLG3b controls grain length and yield in japonica rice. Plant Biotechnol J 16(9):1667-1678

Yun YT, Chung CT, Lee YJ, Na HJ, Lee JC, Lee SG, Lee KW, Yoon YH, Kang JW, Lee HS, Lee JY, Ahn SN (2016) QTL mapping of grain quality traits using introgression lines carrying Oryza rufipogon chromosome segments in japonica rice. Rice 9:62

Zhang Q, Yao GX, Hu GL, Chen C, Tang B, Zhang HL, Li ZC (2012) Fine Mapping of qTGW3-1, a QTL for 1000-Grain Weight on Chromosome 3 in Rice. J Integr Agri 11(6):879-887

Zhang XJ, Wang JF, Huang J, Lan HX, Wang CL, Yin CF, Wu YY, Tang HJ, Qian Q, Li JY, Zhang HS (2012) Rare allele of $O S P P K L 1$ associated with grain length causes extra-large grain and a significant yield increase in rice. Proc Natl Acad Sci USA 109:21534-21539

Zhao DS, Li QF, Zhang CQ, Zhang C, Yang QQ, Pan LX, Ren XY, Lu J, Gu MH, Liu QQ (2018) GS9 acts as a transcriptional activator to regulate rice grain shape and appearance quality. Nat Commun 9(1):1240 Zuo JR, Li JY (2014) Molecular genetic dissection of quantitative trait loci regulating rice grain size. Ann Rev Genet 48: $99-118$

\section{Figures}

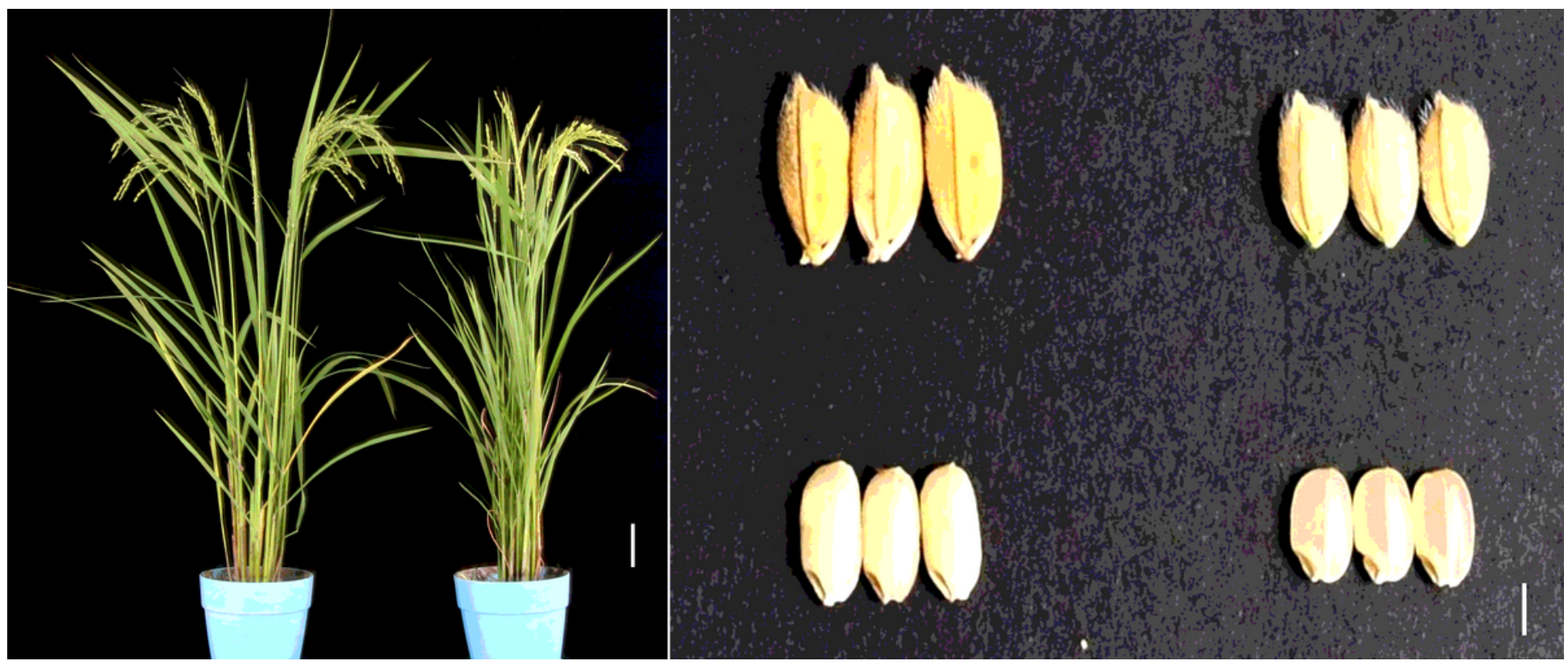

Figure 1 
Comparison of whole-plant rice and grain performance between IL188 and Nipponbare. A, Plant type of IL188 (left) and Nipponbare (right). B, Paddy and brown rice grains of IL188 (left) and Nipponbare (right). Bars: $10 \mathrm{~cm}$ in $\mathrm{A}, 6 \mathrm{~mm}$ in $\mathrm{B}$.

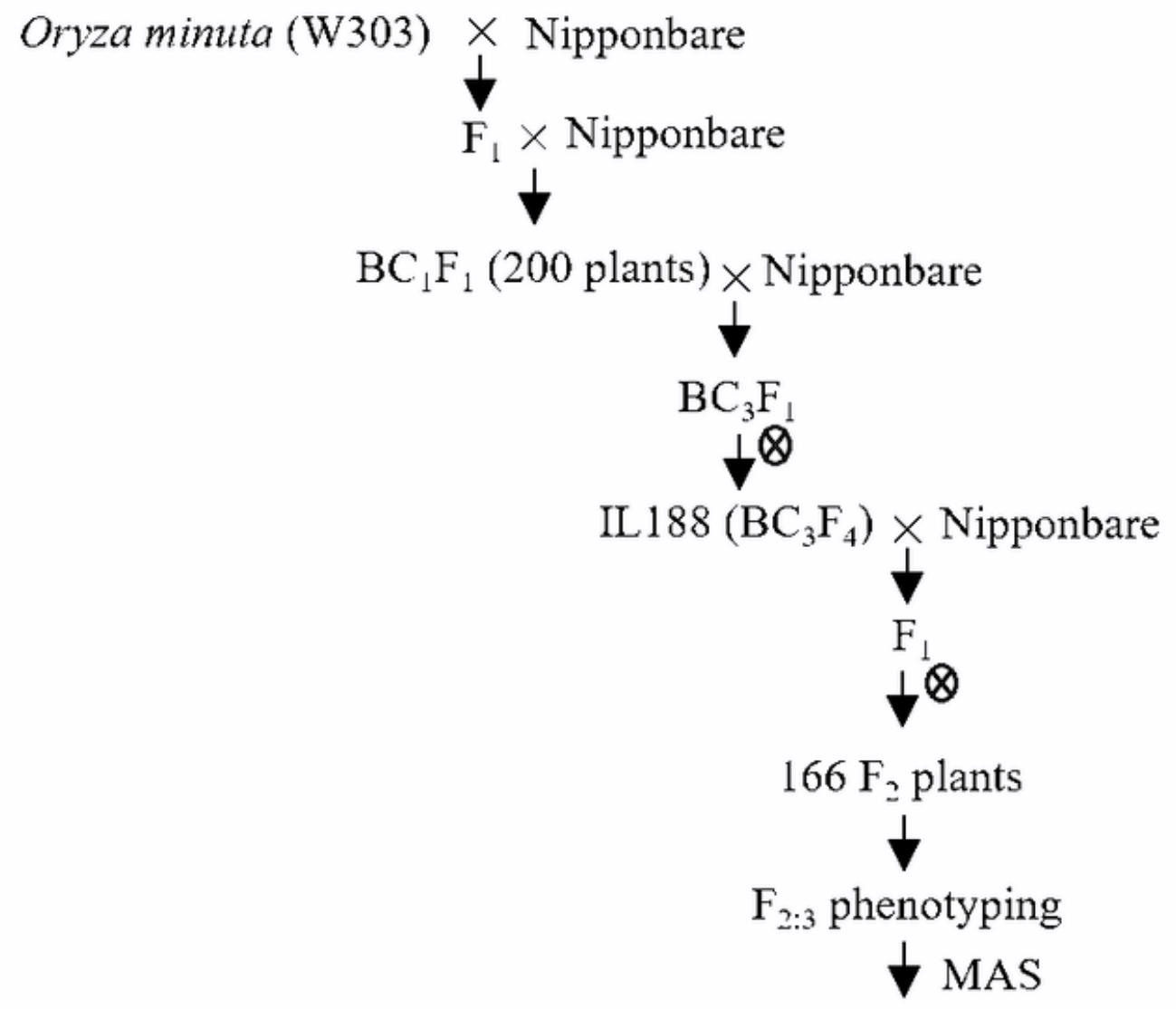

Four plants heterozygous in RM1135-RM11,

RM11-Y7-2, RM11-Y7-2, or RM11-Y7-4

$\perp \otimes$

R1 (180 plants), R2 (184 plants), R3 (184 plants), R4 (195 plants)

$\downarrow$ MAS

Four plants heterozygous in Y7-4-RM21787, Y7-4-

RM455, RM21787-Y7-12, or RM21787-Y7-13

$\downarrow \otimes$

R5 (130 plants), R6 (144 plants), R7 (146 plants), R8 (140 plants)

Figure 2

A scheme showing how plants materials were developed. 

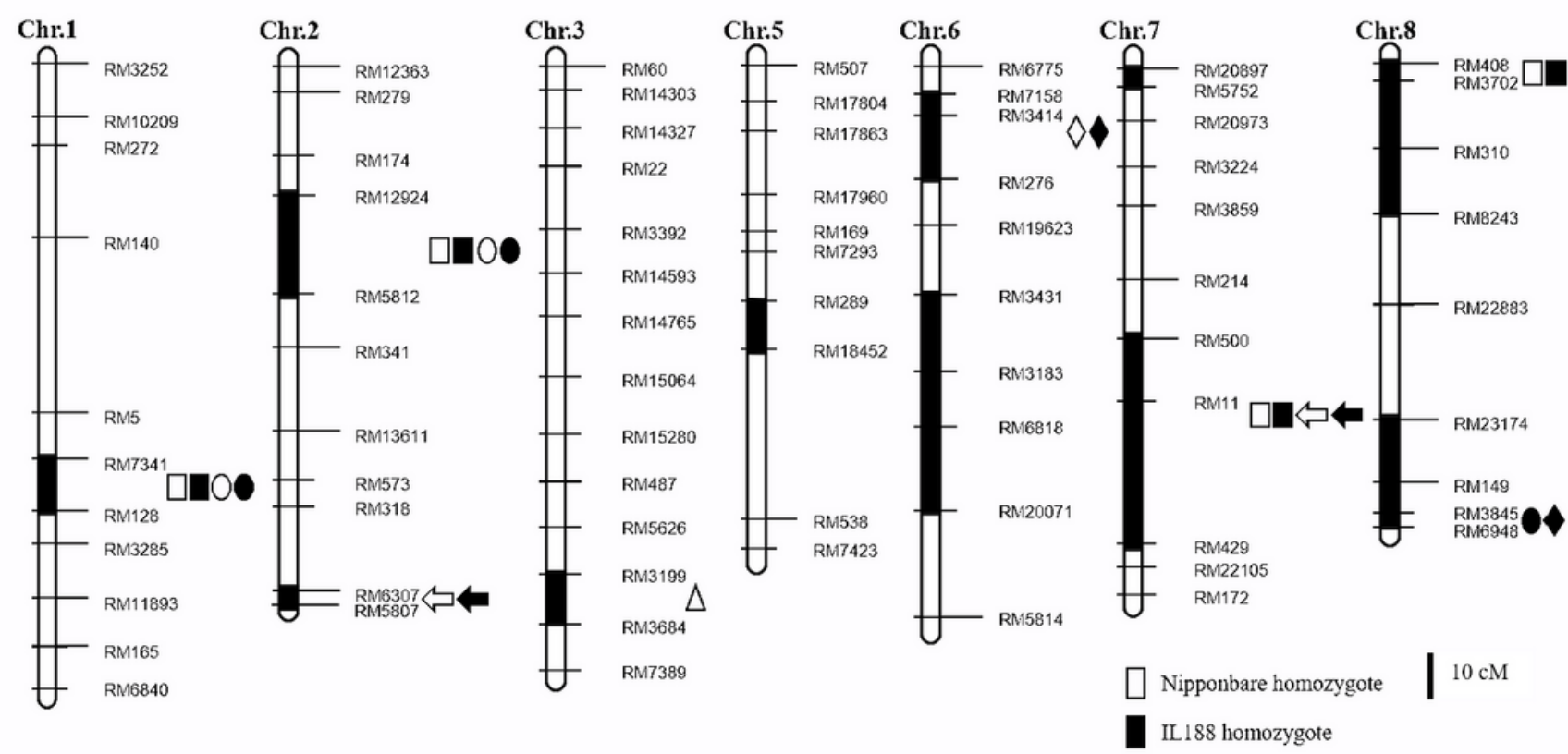

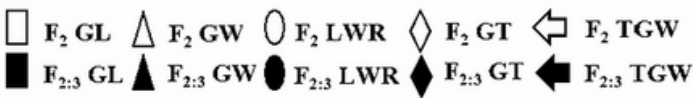

\section{Figure 3}

Genetic linkage map showing QTL positions detected in the F2 and F2:3 Genetic linkage map showing QTL positions detected in the F2 and F2:3 populations. White and black shapes indicate F2 and F2:3 population, respectively.
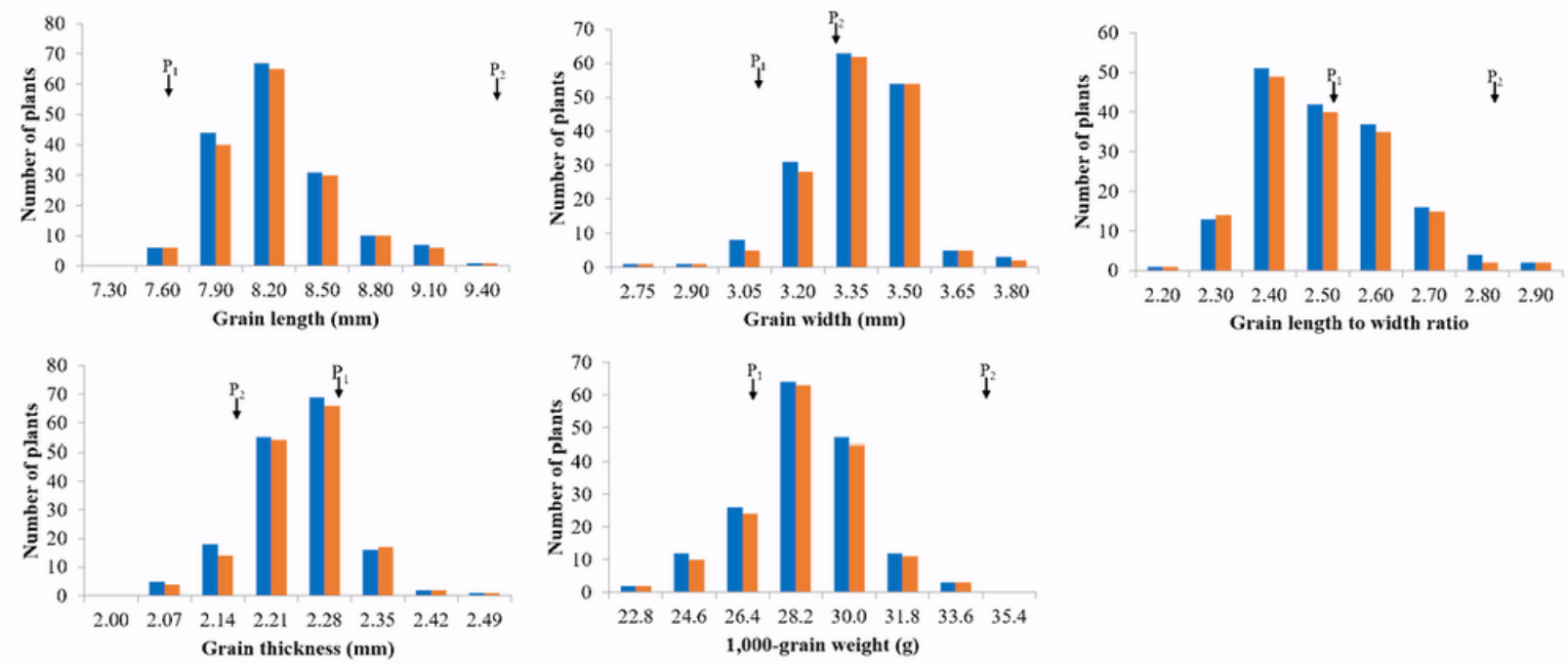

Figure 4 
Frequency distribution of five grain shape traits in the F2 and F2:3 populations. (P1: Nipponbare, P2: IL188). The vertical axis of each figure represents the number of F2 and F2:3 plants, blue bars and red bars indicate $\mathrm{F} 2$ and $\mathrm{F} 2: 3$, respectively.

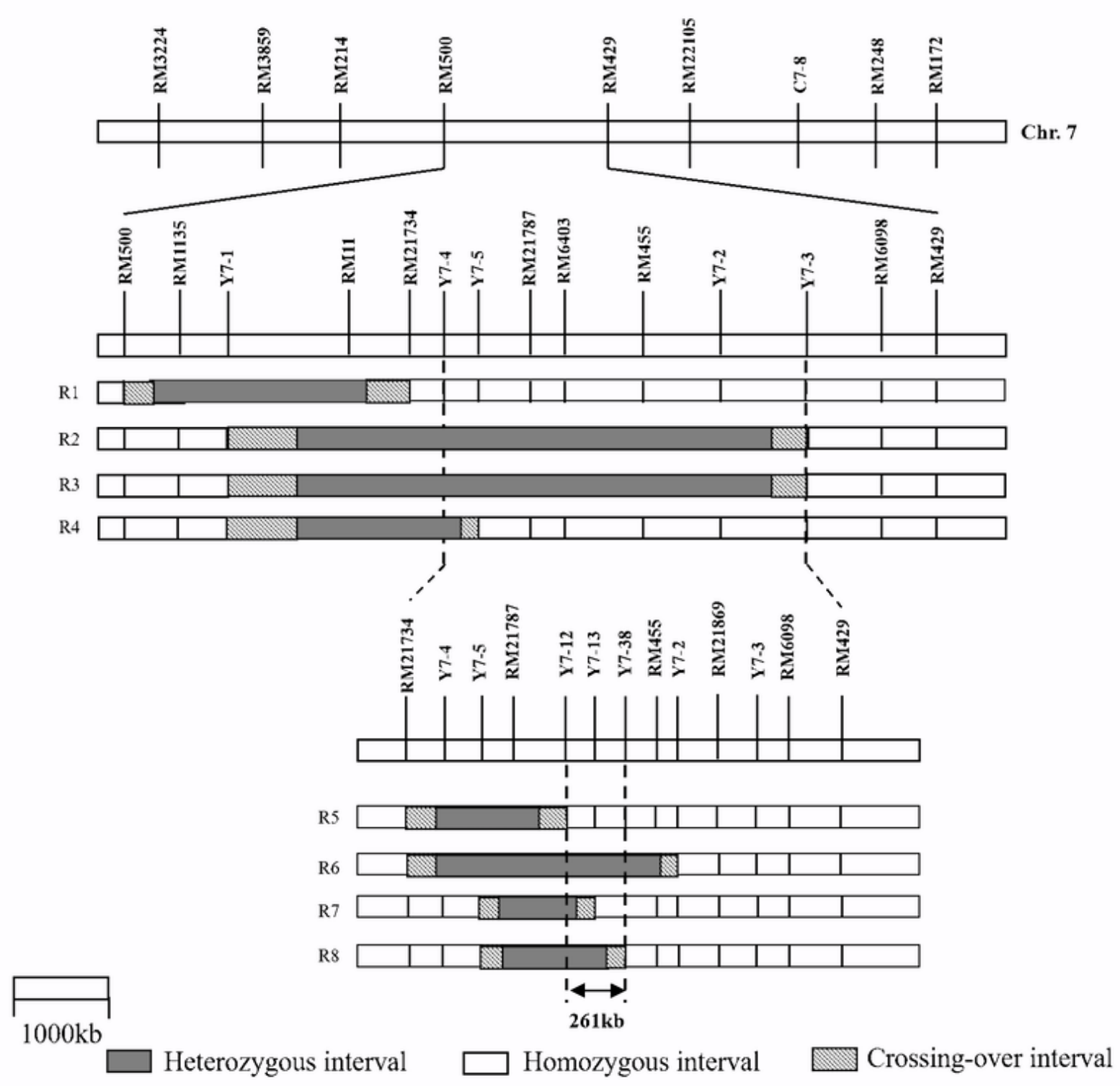

\section{Figure 5}

Genotypes compositions of NIL populations in the target region. NIL, near-isogenic line. 


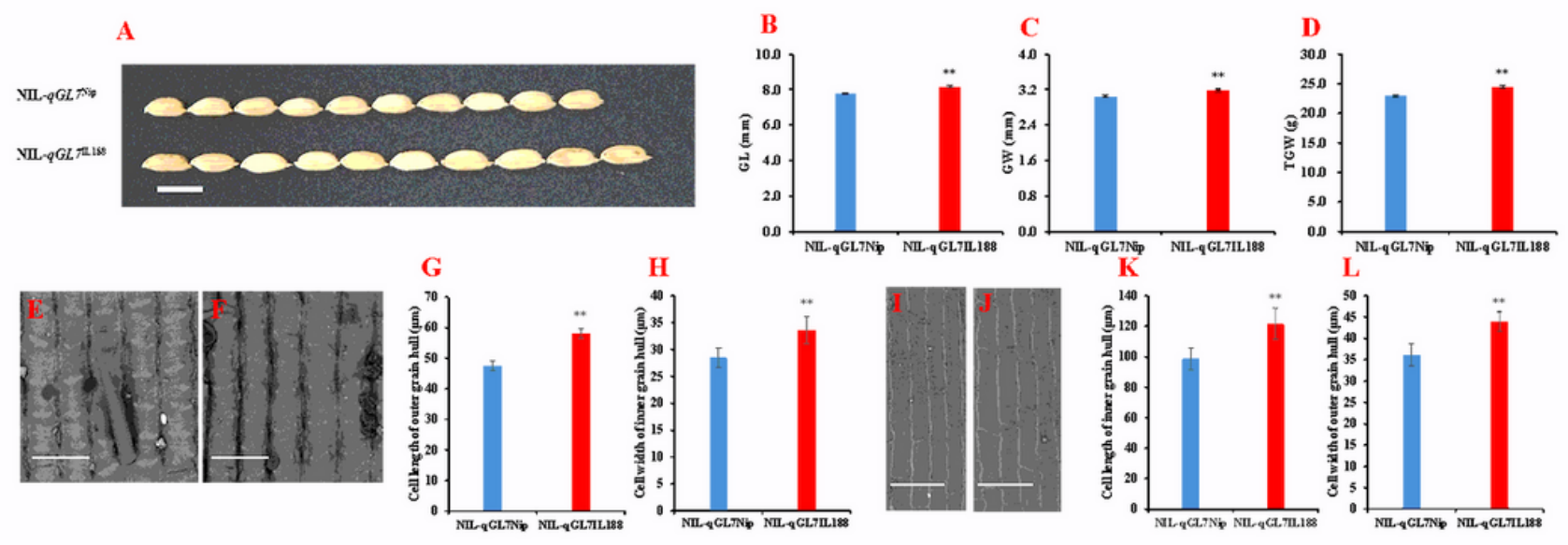

\section{Figure 6}

Comparison of grain size and spikelets epidermal cells between NIL-qGL7Nip and NIL-qGL7IL188. A, Mature grains of NIL-qGL7Nip () and NIL-qGL7IL188. Scale bar, $6 \mathrm{~mm}$. B-D, Grain length (GL), grain width (GW), and 1000-grain weight (TGW) for NIL-qGL7Nip and NIL-qGL7IL188. Data are given as mean $\pm(\mathrm{n}=$ 20). ** indicate significant difference at 0.01 level. E-F, Outer epidermal cells of grain hulls of NIL-qGL7Nip and NIL-qGL7IL188. Bars $=100 \mu \mathrm{m}$. G-H, The average length and width of outer epidermal cells. $(n=10)$. I-J, Inner epidermal cells of grain hulls of NIL-qGL7Nip and NIL-qGL7IL188. Bars $=100 \mu \mathrm{m}$. K-L, The average length and width of inner epidermal cells. $(n=10)$.

\section{Supplementary Files}

This is a list of supplementary files associated with this preprint. Click to download.

- Supplementarytable.pdf 